\title{
UN LEÓN ENTRE LA HACIENDA. RELACIONES ENTRE ANIMALES Y HUMANOS A PARTIR DEL ESTUDIO DE PUMAS EMBALSAMADOS EN LA PUNA DE JUJUY (ARGENTINA)
}

\author{
A LION IN THE FLOCK. RELATIONS BETWEEN ANIMALS AND HUMANS FROM \\ A STUDY OF EMBALMED PUMAS IN THE PUNA OF JUJUY (ARGENTINA)
}

\author{
María Carolina Rivet
}

\begin{abstract}
En distintos lugares de los Andes los félidos son calificados como animales predadores, criados por el cerro y a la vez son considerados pastores y protectores del ganado. En Coranzulí en particular (Jujuy, Argentina) en la actualidad se conservan pumas embalsamados en las casas de campo. Estos tienen la característica de poseer atributos materiales que los vinculan con los animales de los rebaños familiares. Los procedimientos técnicos, tanto para su caza como para la preparación del cuerpo, se plantearían como una de las condiciones necesarias para que sus capacidades otrora riesgosas devengan en propiciadoras. Así, una vez embalsamados, se integran a las sociabilidades familiares al participar activamente de la vida cotidiana de los pastores con agencias tales como la capacidad de multiplico, fertilidad y protección no solo del ganado sino también del grupo familiar.
\end{abstract}

Palabras claves: Pumas embalsamados, pastores-puna de Jujuy.

In different places of the Andes, felids are classified as predators, raised by Coquena, and at the same time, they are considered shepherds and livestock protectors. At present, especially in Coranzuli-Jujuy, Argentina-embalmed pumas are preserved in country houses. They have the distinctive characteristic of having material attributes connecting them to the animals of the flocks. The technical procedures for hunting and preparing the body will be considered one of the necessary conditions for their once risky capabilities to turn into enabling capabilities. Thus, once embalmed, they are integrated into family sociabilities by actively participating in the shepherds' daily life with agencies such as the ability to multiply, fertility, and protection of livestock and the family group.

Key words: Embalmed pumas, shepherds, Puna of Jujuy.

\section{Introducción}

Las referencias arqueológicas, históricas y etnográficas a los felinos, recurrentes en toda el área andina, presentan una gran profundidad temporal, siendo representados en diferentes soportes (cerámica, arte rupestre, escultórica lítica, parafernalia alucinógena, etc.) o utilizando partes de estos animales como pieles o cabezas en tocados y vestimentas ${ }^{1}$. Diferentes crónicas coloniales (como por ejemplo Albornoz 1989, Álvarez 1998 [1588], Ávila 1987 [1551], Betanzos 1987 [1551], Garcilaso de la Vega 1963 [1609], Molina 1989 [1573]), a su vez, mencionan su participación en instancias rituales, en bailes y en festividades, dando cuenta de la complejidad y relevancia de dichos animales para las sociedades andinas. Sin embargo, atañen particularmente para este trabajo las consideraciones que entienden a los felinos como guardianes espirituales del ganado, verdaderos pastores de los cerros, y también un animal sagrado (Arnold 2016, Gavilán Vega y Carrasco 2009, Dransart 2002, Grebe 1984, Martínez 1983, Tschopik 1951). Estas apreciaciones surgen especialmente de la presencia de gatos monteses (titis) embalsamados en las mesas de los rituales pastoriles de marcación del ganado. En Isluga (norte de Chile) es considerado el awatiri del mallku, es decir, el pastor del espíritu de la montaña (García et al. 2018, Grebe 1989/90). Consideraciones similares realiza Arnold para Qaqachaka (Oruro, Bolivia), al entender a los felinos como "verdaderos pastores de los cerros, que protegen a los animales de los rebaños" (2015:126). Es este el punto de partida para nuestro trabajo, en el que nos enfocaremos específicamente al estudio del puma y su vínculo con el mundo pastoril, desde una perspectiva etnográfica, en la puna de la provincia de Jujuy.

En Coranzulí (puna de Jujuy, Argentina), las referencias a los felinos se orientan tanto al puma

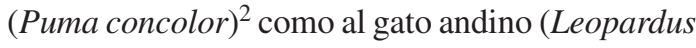

* Consejo Nacional de Investigaciones Científicas y Técnicas - Instituto Interdisciplinario Tilcara (FFyL-UBA).

Correo electrónico: carolinarivet@hotmail.com, rivetcarolina@gmail.com 
jacobitus), con algunos puntos en común. Ambos son considerados peligrosos para la hacienda, siendo el primero el principal predador, pudiendo diezmarla y presentando incluso riesgos para las personas, así como refieren las personas en nuestra área de estudio. Es decir, lo que los pastores puneños expresan verbalmente, y en una primera instancia, está cargado de connotaciones negativas. Concepciones similares se han registrado también en otros sectores del noroeste argentino, por ejemplo para Catamarca (Cruz 2002 y Villar 2015) y para Jujuy (Carrizo 1959 [1934] y Pazzarelli 2019). Sin embargo, una mirada más situada en las relaciones locales nos permite entrever que el rol del puma ofrece múltiples aristas. Las relaciones que se establecen con estos felinos son mucho más ambiguas y complejas de lo que se percibe de los comentarios cotidianos que se realizan de sus riesgos para los rebaños y las personas. De hecho, como analizaremos más adelante, para comprender estas apreciaciones debemos diferenciar entre el estado vivo o exánime de dicho animal.

$\mathrm{Al}$ entrar en las casas de campo es relativamente habitual encontrar el cuerpo embalsamado de un puma colgando del techo, específicamente de la cumbrera. Se trata de grandes felinos, completos, adultos y de gran porte, con una coloración parda y uniforme (Figura 1). Su presencia nos invita a la complejidad de la comprensión del rol de los felinos en las sociedades andinas. Tanto las características materiales como los relatos acerca de los procedimientos y las significaciones con otras entidades que el puma puede encarnar serán el eje de nuestro trabajo. Nos interesa analizar la red de relaciones en la que se inserta el puma, que involucra otros animales (domésticos y "salvajes") y otras personas humanas y no humanas, en un contexto pastoril, a partir del trabajo de campo etnográfico que venimos realizando desde hace varios años en el área. Atenderemos particularmente a cómo aquel animal predador y cazador de la hacienda, bajo determinadas circunstancias es también protector y potenciador de la fertilidad. Esta situación nos expone a reflexionar acerca del carácter ambivalente, genésico y relacional de ciertas entidades en los Andes. El siguiente trabajo se basa en el análisis de seis pumas pertenecientes a diferentes familias coranzuleñas y en los relatos recogidos entre pastores de dicha localidad. Dichos relatos son referidos a determinadas instancias del derrotero del puma, como su comportamiento, las maneras de cazarlo o las técnicas para embalsamarlo. Sin embargo, las

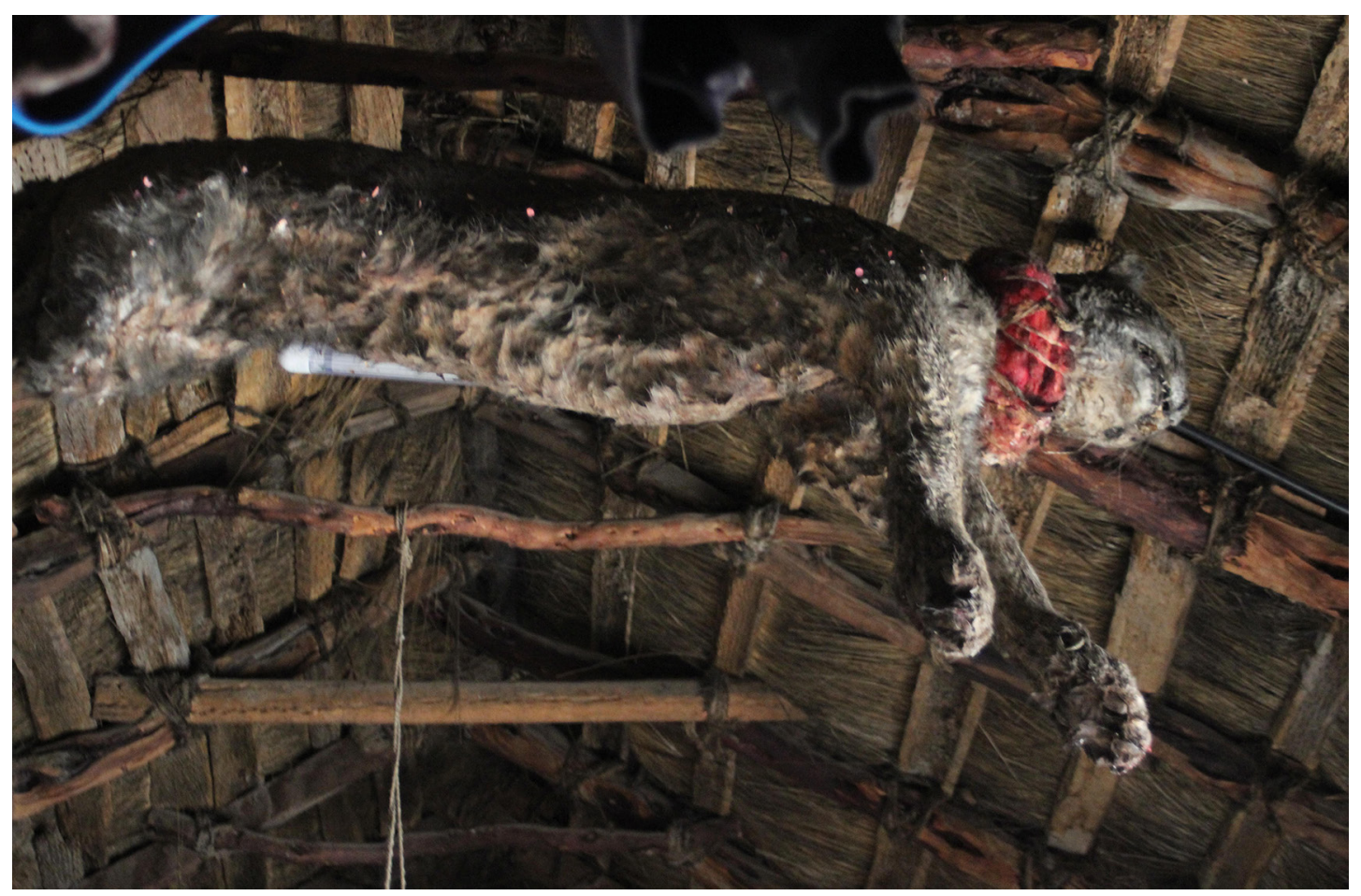

Figura 1. Puma embalsamado colgando de la cumbrera del techo. 
personas no se refieren oralmente ${ }^{3}$ a los sentidos de estos felinos cuando ya están colgados en sus casas, sino que se vinculan con ellos de manera performática. Son también estas acciones las que hemos observado y registrado.

\section{El área de estudio}

El pueblo de Coranzulí está ubicado dentro del departamento de Susques, en la provincia de Jujuy, a $95 \mathrm{~km}$ al sudoeste de la localidad de Abra Pampa (Figura 2). Los territorios de pastoreo correspondientes, que se despliegan en torno al poblado, se encuentran organizados en tres secciones, que a su vez en ciertas ocasiones organizan también socialmente a la población: Incahuasi, Quebrada Grande y Agua Delgada. En términos ambientales el área de trabajo se emplaza dentro de lo que se conoce como puna, es decir, una planicie de altura semidesértica por encima de los
$3.000 \mathrm{msnm}$ (Cabrera 1976). Esta altiplanicie se encuentra atravesada por numerosas quebradas y cerros que pueden configurar ciertos microclimas. El área puneña en general presenta un clima frío y seco, con una gran amplitud térmica diaria, y lluvias casi exclusivamente en época estival, que disminuyen de norte a sur, siendo muy escasas en su porción meridional. Coranzulí formaría parte de lo que se conoce como Puna Seca (Cabrera 1976) que presenta una mayor humedad, con formación de lagunas, ríos de agua permanente y una vegetación relativamente continua.

El empleo público, el trabajo en los emprendimientos mineros y el comercio conforman actividades económicas que emplean buena parte de la población. Más allá de la importancia que puedan tener hoy estas ocupaciones en términos de ingresos, es posible sostener que el pastoreo extensivo de rebaños mixtos (camélidos, ovinos, caprinos y, en algunos casos, vacunos) sigue siendo una actividad central

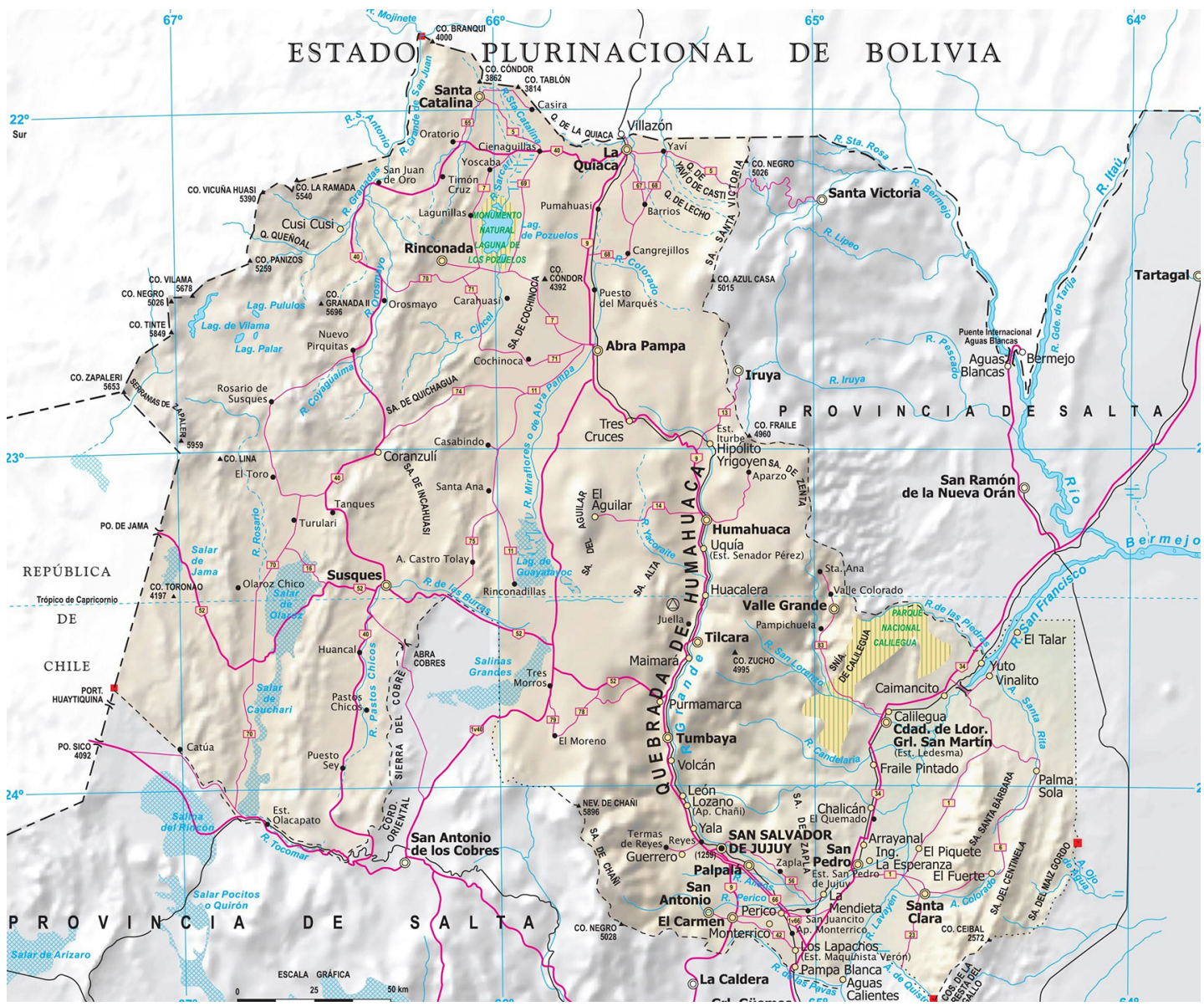

Figura 2. Ubicación del área de estudio. Fuente: Instituto Geográfico Nacional - Argentina (Modificado por la autora). 
en términos sociales, rituales y, en menor medida, económicos. Se puede observar que estas prácticas responden, en términos generales, a lo que ha sido propuesto respecto de la movilidad y las lógicas de asentamiento para áreas cercanas como Susques y Huancar (Göbel 2002, Tomasi 2011, Yacobaccio et al. 1998). Es decir, cada unidad doméstica posee una cierta cantidad de asentamientos, con uno principal ("casa de campo" o "domicilio") y una serie de "estancias" o "puestos", que son recorridos siguiendo un cierto ciclo estacional. Como ha sido observado en las localidades mencionadas, cada una de estas unidades domésticas controla un territorio de pastoreo de uso exclusivo (Göbel 2002, Tomasi 2011).

El puma forma parte de las redes de relaciones pastoriles. No lo podríamos conceptualizar por fuera de ese universo pastoril, de sus espacialidades, prácticas y sentidos. Como veremos más adelante, este animal se integra a la vida familiar en tanto se ubica dentro de la casa de campo, y en relación con los atributos que lo vinculan a los rebaños.

\section{Un león en el cerro. Los pumas como hacienda de Coquena}

De acuerdo con los coranzuleños, el puma, o león, es del cerro, y es criado por Coquena ${ }^{4}$, al igual que otros animales "no domesticados" como la vicuña, la vizcacha, el zorro, entre otros. En general el puma evita el contacto con las personas, no siendo común que se acerque a los domicilios. Es así como suele atacar de noche a los animales del rebaño que pudieron quedar perdidos en el cerro, especialmente a las crías (uyñita), o a las tropas que por alguna razón quedaron lejos del cuidado de los pastores y las pastoras ${ }^{5}$. Las familias sostienen que los ataques se han intensificado en los últimos tiempos, ya que muchos rebaños permanecen solos por períodos prolongados, debido a que los pastores no visitan sus campos con la regularidad que antes lo hacían.

Los pastores están permanentemente alertas a las señales que dan cuenta de la cercanía de este predador (así como huellas y crías muertas de la hacienda) y al detectarlas se suelen seguir ciertas estrategias para cazarlo o ahuyentarlo. Para espantar al puma, en las casas de campo siempre está el fuego encendido en la kancha (la cocina externa) y, de hecho, cuando detectan que el león anda deambulando, prenden fogatas en los lugares donde se localizan sus pisadas y por donde andan generalmente los rebaños.

Además el león le teme a la mujer. La mujer consigue doblegarlo mostrándole sus genitales y, mejor aún, orinando. Un vecino ${ }^{6}$ de la comunidad comenta que en una ocasión su hija se cruzó con un puma y entonces ella "se levantó la pollera y orinó y el puma se echó. El puma le tiene más miedo a la mujer. Entonces la mujer es más poderosa que el puma porque puede con él"7. Existen referencias similares para otros sectores de los Andes, tal como lo muestra Zuidema (1989:318) al referir que cuando un puma mata el ganado "los hombres salen a cazarlo acompañados siempre por una mujer cuya presencia lo debilita según se cree".

Es interesante notar, con relación al ejemplo de Coranzulí, la capacidad de discernimiento que muestra el puma, que mira como persona humana al poder reconocer a la mujer a partir de identificar visualmente sus genitales. De hecho, esta no es la única capacidad que se le reconoce al león, que es descrito en los siguientes términos: "de noche sus ojos son como linternas, tiene poder, tiene vista, tiene olfato, silba como gente para llamar a las llamas, las engaña"8. A su vez, otros pastores destacan también la habilidad de cargar la presa "como lo hace una persona, como lo hacemos nosotros, a sus espaldas, yo lo he visto, cómo será eso? Cómo es que podrán hacerlo?" 9 . Estas capacidades del puma son admiradas y destacadas por dichos pastores. Asimismo, se dice que los pumas "tienen arte". ¿Qué significa "tener arte" en la puna? Significa, en términos locales, que te atrae, te domina, te hipnotiza, te vuelve sonso, te vuelve callado, te mira y te quedas mudo. Ese arte hace que el animal cazado caiga en su dominio.

\section{La caza y el embalsamado del león}

Cazando vicuñas anduve en los cerros.

Heridas de bala se escaparon dos.

-No caces vicuñas con arma de fuego,

Coquena se enoja - me dijo un pastor (...)

Juan Carlos Dávalos, La leyenda del Coquena

Como dijimos, cuando se detecta que el puma anda merodeando los alrededores, los pastores lo ahuyentan con fuego, pero en algunos casos, los cazan. Si bien varía la forma o la técnica empleada, existe consenso en una cuestión puntual: el puma (al igual que otros animales de Coquena) no debe 
ser cazado con arma de fuego. Sin embargo, en algunos relatos aparecen "las balas". Cuando esto sucede, es decir, cuando se intenta cazar al león con armas, siempre se fracasa, especialmente si quien dispara es un varón. Se suele decir: las balas no le entraron, las balas le rebotaron. La relación con los varones es entonces diferente de la de las mujeres ${ }^{10}$. "El puma no les teme e incluso presenta resistencia a las balas si estos les dispararan". Se comenta que "tiene poder: acalla los perros, frena las balas, que no le entran ni por la cabeza, no atraviesa el cráneo, ni por el lomo". Y otro vecino agrega "no sale la bala y si sale no entra si ve pantalones [es decir si es un varón el que tira]"11.

En relación con su captura hemos registrado dos técnicas:

- Con trampa: Cuando identifican que merodea el puma se juntan a la noche, y siguen sus huellas. Se esconden entre las peñas en un lugar determinado. Ponen de señuelo una cría (que puede ser de llama, oveja o cabra) y una trampa metálica, tipo cepo, que los pastores describen como las dientudas, que sujetan al animal por una extremidad. Cuando el puma cae en ella agarrado por una pata, se acercan y lo matan generalmente con un golpe realizado con una piedra. Lo importante es que el animal no sangre ni se destroce.

- Machándolo con chuscho ${ }^{12}$. Hacen un bolo de carne al que le agregan este yuyo (curamos la carne con chuscho), y lo colocan en los lugares donde frecuenta el león. Este lo come, queda atontado y es fácil agarrarlo. Al igual que en la técnica anterior le dan un golpe en la cabeza con una piedra para finiquitarlo.

La cacería del puma implica, por un lado, un conocimiento de la etología de dicho animal, particularmente sus hábitos y recorridos y, por otro, un gran cuidado para no destrozarlo manteniendo su integridad física para luego poder ser embalsamado. Una vez sacrificado el puma es trasladado al domicilio familiar en el campo, donde se inician varios procedimientos para la remoción de los órganos, seguido de una deshidratación facilitada por el agregado de estiércol y el mismo clima seco, que genera una forma de embalsamado "casero". Se trata de una técnica muy pautada, casi sin variaciones, que se detalla a continuación.
En primer lugar se eviscera el animal, por medio de un corte interno en los cuartos traseros, por donde se sacan los órganos, quedando los huesos, la carne y los sesos, que se secan con el tiempo, de forma natural favorecido por las condiciones ambientales puneñas. Luego del evisceramiento, se rellena la cavidad abdominal con guano ${ }^{13}$ de llama y se deja secar a la sombra. El cuerpo se rota regularmente para mantener la forma y remarcar gestos. Es en esta instancia donde se resaltan las fauces, se rellenan los pómulos (a veces incluso con hojas de coca, ver Figura 3), las patas son extendidas y las garras abiertas en actitud amenazante. Una vez seco, se extrae el guano ${ }^{14}$, se rellena con vellón de lana de llama y se realiza una costura lo más sutil posible (Figura 4). Por lo general estos animales embalsamados perduran por mucho tiempo y suelen ser las polillas u otros insectos la razón de su deterioro. Cuando se arruina, la manera de descartarlo es por medio de su quema. Esta es la única forma que hemos registrado de deshacerse de ellos.

Todo este procedimiento apunta a una intención: el aspecto del animal. Lo que se busca es que parezca

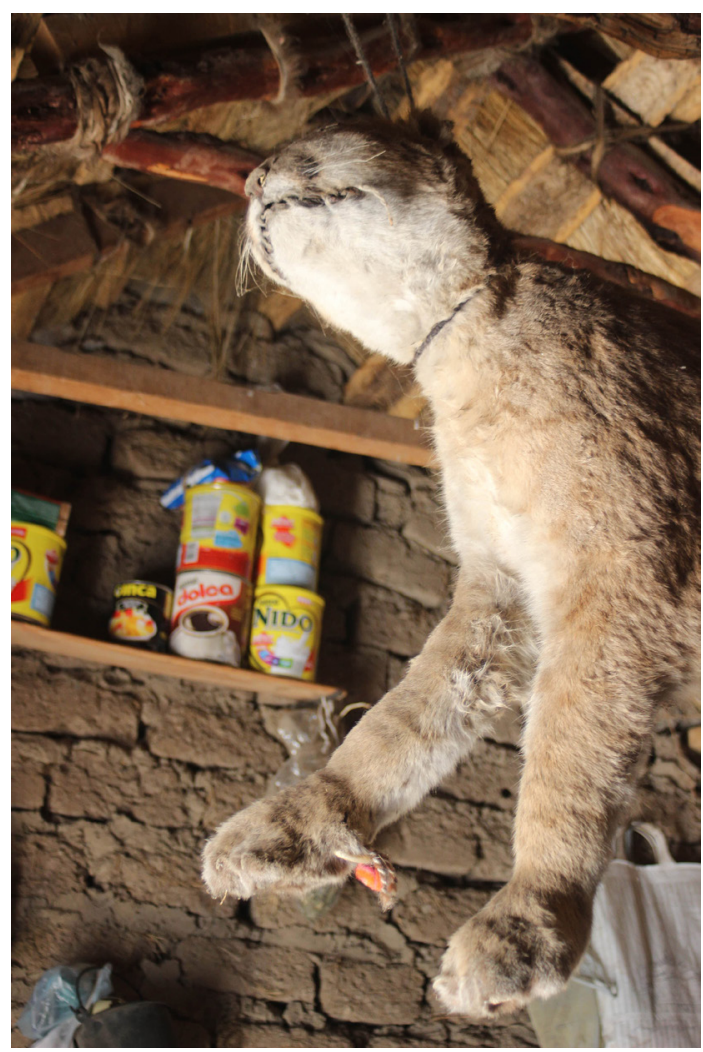

Figura 3. Operaciones para el embalsamado. Obsérvese detalle en el puma del pómulo relleno. 


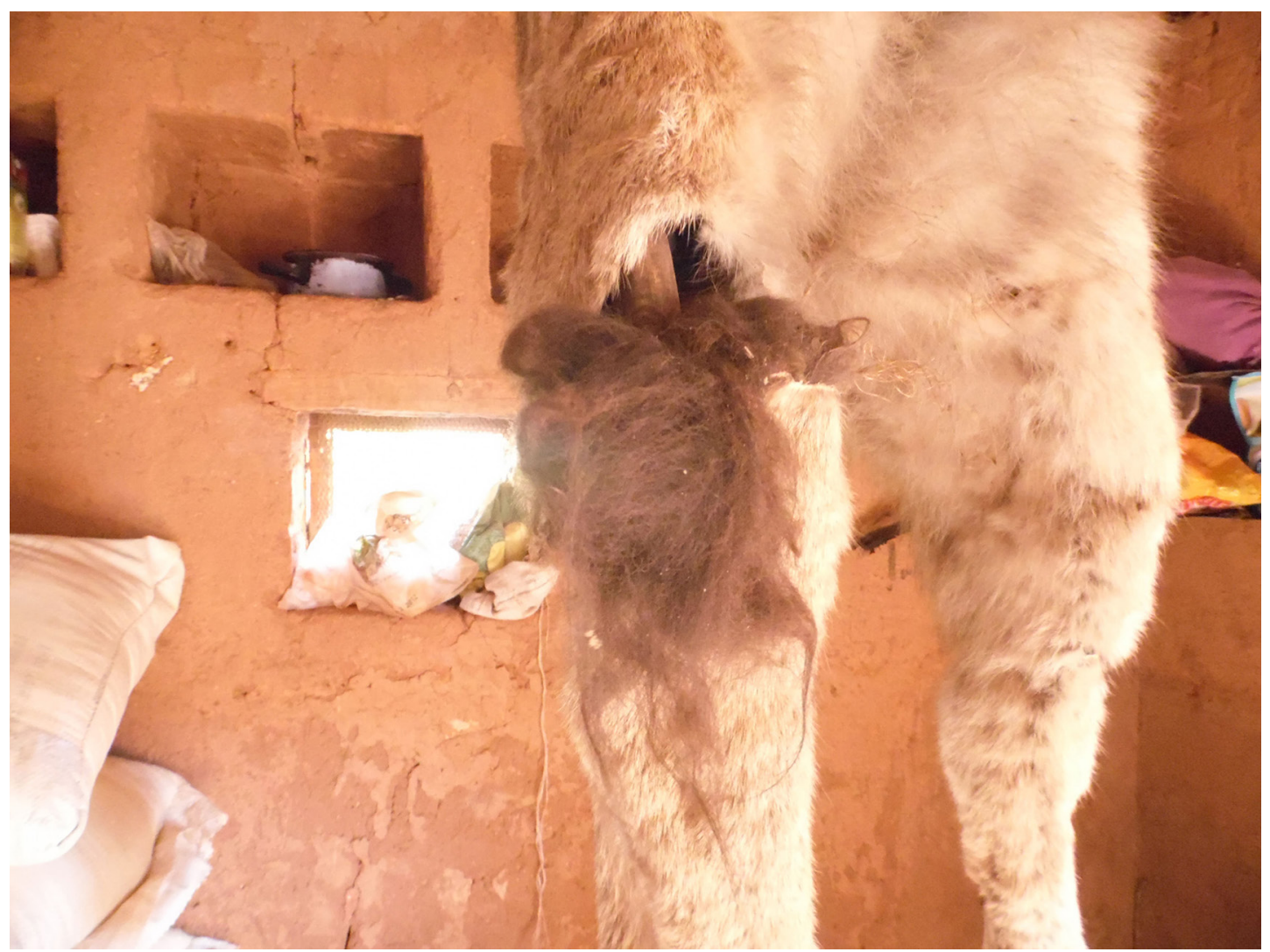

Figura 4. Operaciones para el embalsamado. Detalle del relleno.

vivo y en posición activa. Podemos pensar que se está manufacturando, de alguna manera, un nuevo ser; con todas estas operaciones se está criando un nuevo puma que, al contener en su interior los vellones de lana de llama, estaría conservando la "entidad anímica" de la llama, es decir, su ánimu, en los términos de Bugallo y Vilca (2011:35).

Nos preguntamos entonces si no habría que pensar en qué es lo que se busca retener en el puma y de qué manera, ¿es en su pelaje, en sus garras, en su corporalidad que se intenta mantener su ánimu y su suerte? Pazzarelli (2019), al respecto, ha registrado en el área de Huachichocana (Quebrada de Humahuaca) que una vez desollado el animal ${ }^{15}$, las carnes y las vísceras conservan la suerte.

\section{Un león en la casa. El puma bajo el dominio de la familia}

Una vez que el puma está completamente seco, relleno y zurcido, entra en la casa de campo. Se cuelga de la estructura de madera del techo, específicamente del torillo de la tijera, orientado hacia el este y, cuando coincide, hacia la puerta (ver Figura 1). El recinto elegido para ubicar el puma es, en general, el destinado a la despensa. Estos animales de gran tamaño, abarcan el ancho de la habitación. Su apariencia viva, activa y agresiva le otorga una imponente presencia que no se puede soslayar.

Estar en la casa es parte de lo que define a este puma. Por tanto, el hecho de que se ubique en el domicilio y el lugar que ocupa dentro de la casa es un tema en sí mismo. Por un lado, la casa de campo es el lugar donde se concentran los principales rituales de la unidad doméstica y el más complejo en términos arquitectónicos, constituyéndose como una referencia de la familia dentro del colectivo comunitario. Además, el puma cuelga del maderamen. Como es sabido, en los Andes en general y en la puna en particular, el techo posee una importancia en sí misma en la conformación de una casa andina como tal (Arnold 1998, Tomasi 2011, Gose 1991, Sendón 2004) siendo objeto de rituales propios, tal como la flechada ${ }^{16}$ (Figura 5), 
que en términos muy generales y sintéticos, es el ritual de inauguración de una casa y de la protección de la familia (Bugallo 1999, Tomasi 2011). Además, desde el interior, los techos se constituyen como auténticos almacenes en los que se disponen distintos objetos valiosos entre las costaneras o las tijeras (Arnold 1998, Göbel 2002). Por otro lado, el techo se vincula con los abuelos, con conceptos relativos a la ancestralidad, lo que se evidencia a partir de la existencia de las casas mochas, casas que, luego de la muerte de sus habitantes, no son vueltas a utilizar, teniendo como característica la falta del techo, y pasando a ser consideradas como las "casas de los abuelos" (Rivet y Tomasi 2016).

Así, el puma pende del techo de la despensa, recinto destinado a guardar y preservar la mercadería. Las despensas suelen estar colmadas de productos diversos tales como charqui, costales de maíz y otros abarrotes; a su vez, de sus techos y paredes cuelgan también mazorcas (pirgüas), ristras de ajos $\mathrm{y}$ otros objetos que suelen estar rodeados con lanas de colores (chimpeados). Estos objetos/sujetos están asociados a la suerte, la reproducción y la fertilidad y, citando a Bugallo (2014), esta suerte debe quedar encerrada dentro de la casa, no debe escaparse. Con todos ellos convive el puma. Es en el techo donde dicho animal se integra a una red de relaciones en que cada uno de ellos se define mutuamente.

En relación con todas estas consideraciones, podemos también definir al puma como samiri o Ylla. En este sentido, es sugerente que entre los grupos aymara "los samiri [potencias gestadoras de la naturaleza] pueden ser amuletos de animales o de personas y tienen diversas representaciones; piedras, gatos monteses embalsamados, etc. Sus significados parecen muy cercanos a los del término illa" (Cereceda 2010: 114). De hecho, Manríquez (1999) en un detallado estudio acerca del término Ylla, también lo vincula con el león o koa, es decir, el felino mítico vinculado con los fenómenos meteorológicos.

Por último, el puma está orientado hacia la puerta, en cierto modo protegiendo el ingreso. Las puertas de entrada a las casas (generalmente orientadas al este) son un punto crítico, un espacio liminal, en tanto pueden permitir ingresos, muchos de ellos peligrosos, y suelen ser protegidas, por ejemplo, con cuchillos clavados al costado de las jambas (Tomasi 2011). El puma entonces se constituiría como una especie de guardián de la intimidad doméstica ${ }^{17}$.

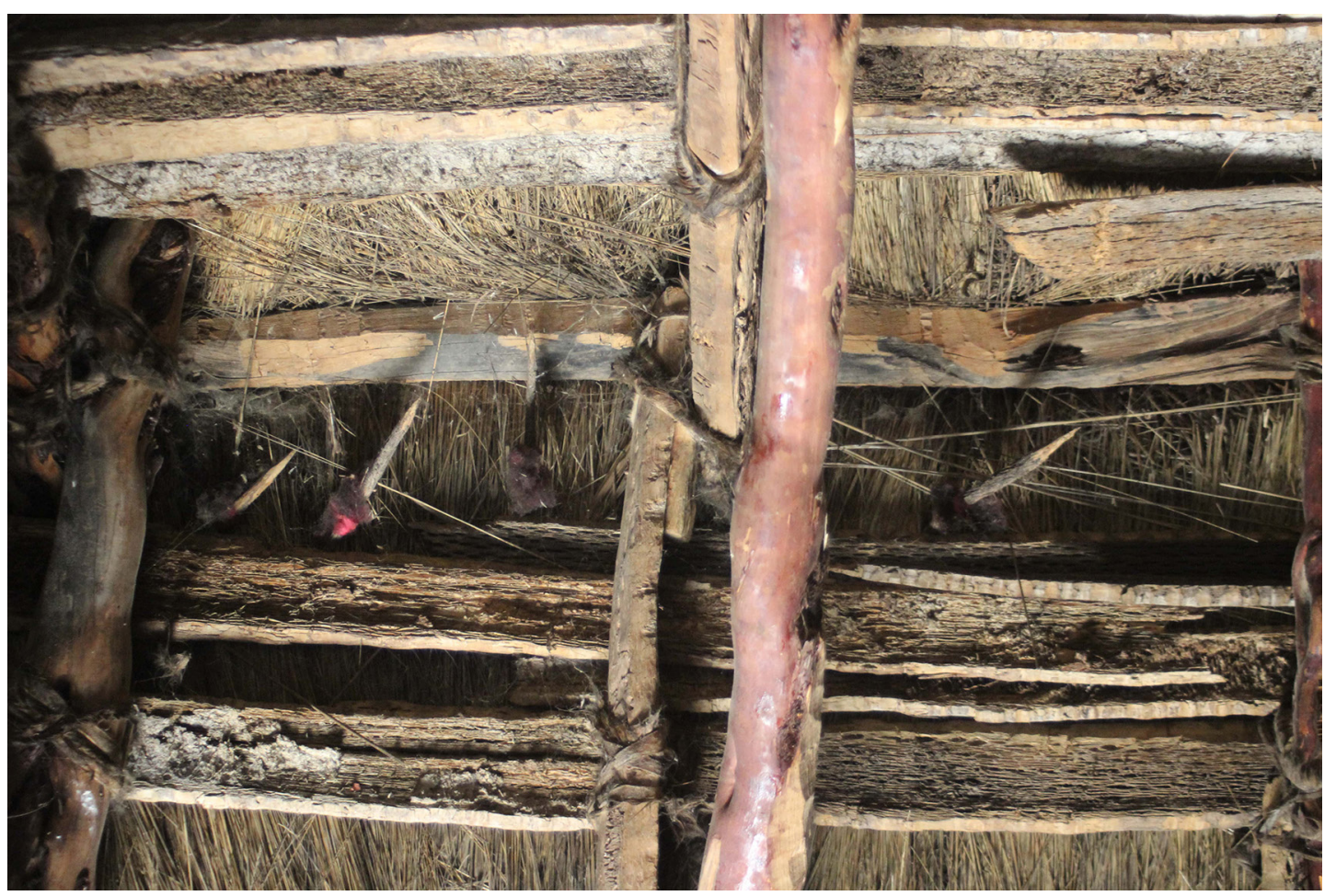

Figura 5. Flechas de la flechada incrustadas en el techo. 
Todas estas consideraciones y prácticas que se realizan acerca de las techumbres de las casas nos aproximan a los sentidos y significaciones que tiene tanto el puma como el techo y las despensas.

\section{Un león enflorado}

Ahora bien, estos pumas tienen, a su vez, la particularidad de estar floreados, chimpeados, de presentar "collares", lo que los vincula directamente con la hacienda familiar (Figura 6). Las flores, chimpus, collares y pecheras son adornos de lana de color que se le colocan a los animales de las tropas (llamas, ovejas, cabras e incluso vacas) durante el ritual de la señalada ${ }^{18}$, es decir, en el ritual andino de producción y reproducción del ganado, de propiciación de la fertilidad y el multiplico, donde los animales de la hacienda son marcados por medio de cortes en las orejas, chimpeados y enflorados. De alguna manera, son incorporados a la familia (entendidos como parientes) por medio de vínculos afectuosos y estableciendo relaciones de crianza mutua (Bugallo y Tomasi 2012, Palacios Ríos 1977). Estas flores y chimpus con sus colores "remiten a la identidad y el vínculo con la familia" (Bugallo y Tomasi 2012:210). De acuerdo con estos mismos autores, cada una de ellas tiene su color, heredándose por generaciones. Y, en la puna de Jujuy, ciertos colores remiten a la alegría, al multiplico y la reproducción como el anaranjado, el guindo, el rosado y otros al duelo y luto, como el morado, negro y azul (Bugallo 2014). Los primeros son los que presentan los adornos del puma.

¿Qué significa entonces que estos pumas estén chimpeados y floreados? De alguna forma están siendo incorporados a la familia del mismo modo que sucede con la hacienda. Y, entendemos, de igual manera, que estos atributos que sostiene el puma están ejerciendo agencias asociadas con la suerte y el multiplico.

Así como mencionamos, la participación de felinos (pumas y gatos monteses) en los ritos de enfloramiento ha sido registrada en otros lugares de los Andes como por ejemplo el norte de Chile

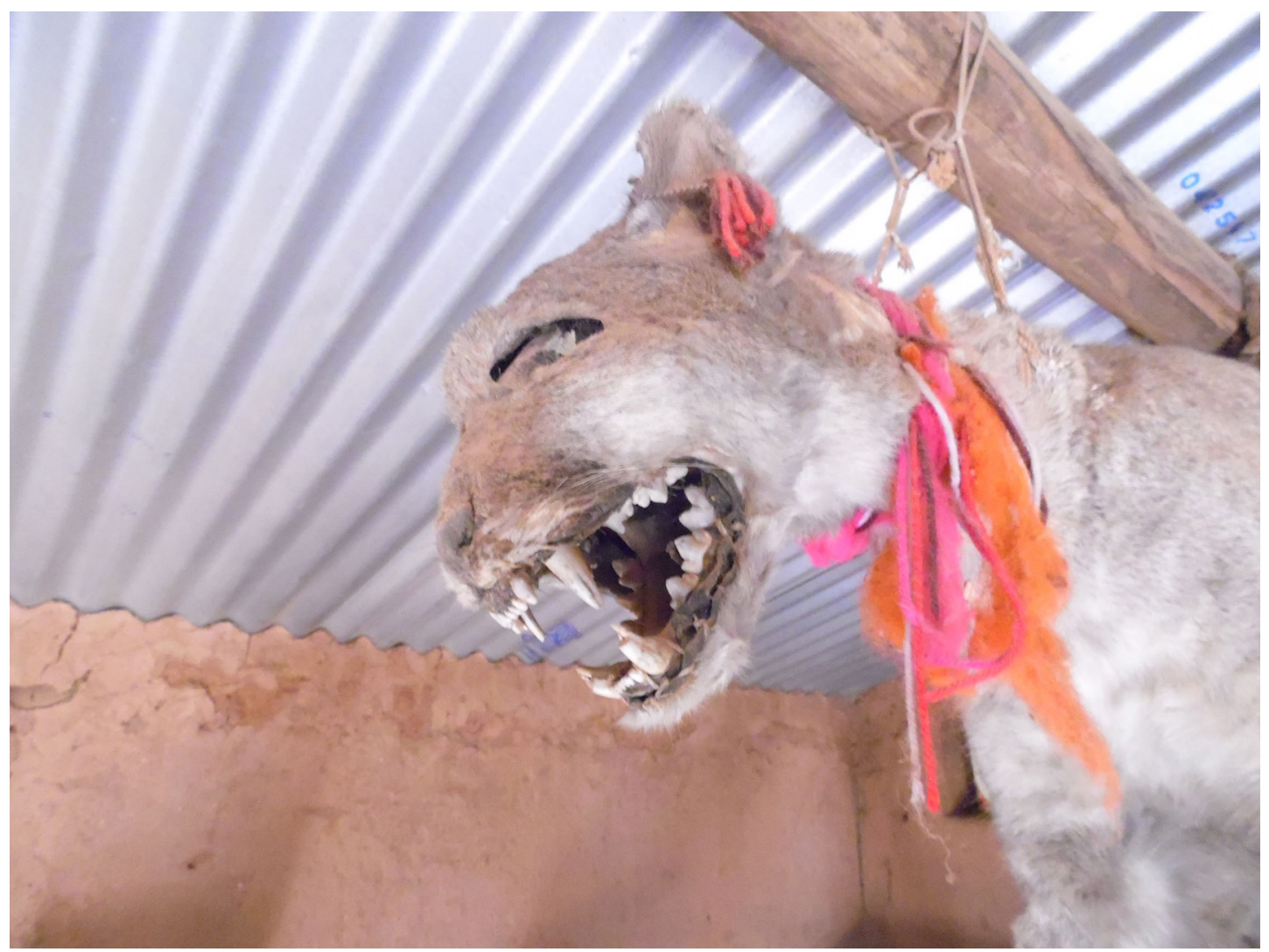

Figura 6. Detalles de flores y collar en el puma. 
(Grebe 1984, Dransart 2002) y en el área aymara (Tschopik 1951). Sin embargo, nosotros no hemos registrado para nuestra área de estudio estas prácticas en las mesas de las señaladas. El vínculo en este caso está dado por los atributos (adornos) que comparten rebaños y pumas embalsamados, por la lana de llama en su interior, y por la colocación de guano durante el proceso de desecamiento, como referimos en los acápites anteriores.

\section{Un león en el pueblo}

Una vecina tiene un puma colgado del techo de su casa en el pueblo. Se lo regaló hace varios años su abuelo, quien lo tenía en su casa de campo. Es ella quien lo traslada y lo cuelga en el techo de chapa del salón principal de la vivienda. Este puma muestra atributos diferentes a los que exhiben los del campo (como vimos, chimpus, flores, collares, etc.), estando adornado con los atributos del carnaval: la serpentina y la mistura (Figura 7), que en algunos lugares como el norte de Chile, es entendido como el "floreo de la gente" (Gavilán Vega y Carrasco 2009). De hecho, a este puma lo chayan para el carnaval del pueblo (distinto al de coplas en el campo, siendo mucho más urbano y de incorporación relativamente reciente en la puna). Es también suerte y protección, pero esta vez se asocia de manera más directa al grupo familiar y a la casa. Es interesante observar cómo al incorporarse a un contexto urbano, alejado de los espacios estrictamente pastoriles, este puma se integra a sus prácticas y significaciones sin perder sus sentidos primigenios, es decir, no se vuelve un objeto de decoración, puramente estético.

En el momento de matar a este puma el golpe que recibió provocó una deformación no esperada en el cráneo, lo que generó una cierta apariencia benévola que luego se intentó resolver colocándole una bolsa de plástico rojo (la sangre de su presa) en la boca para otorgarle un aspecto vivo y feroz, bravo, y en las cavidades orbitarias, a modo de ojos, sendas bolitas de vidrio. Estos agregados se volvieron necesarios para sumar a la apariencia de

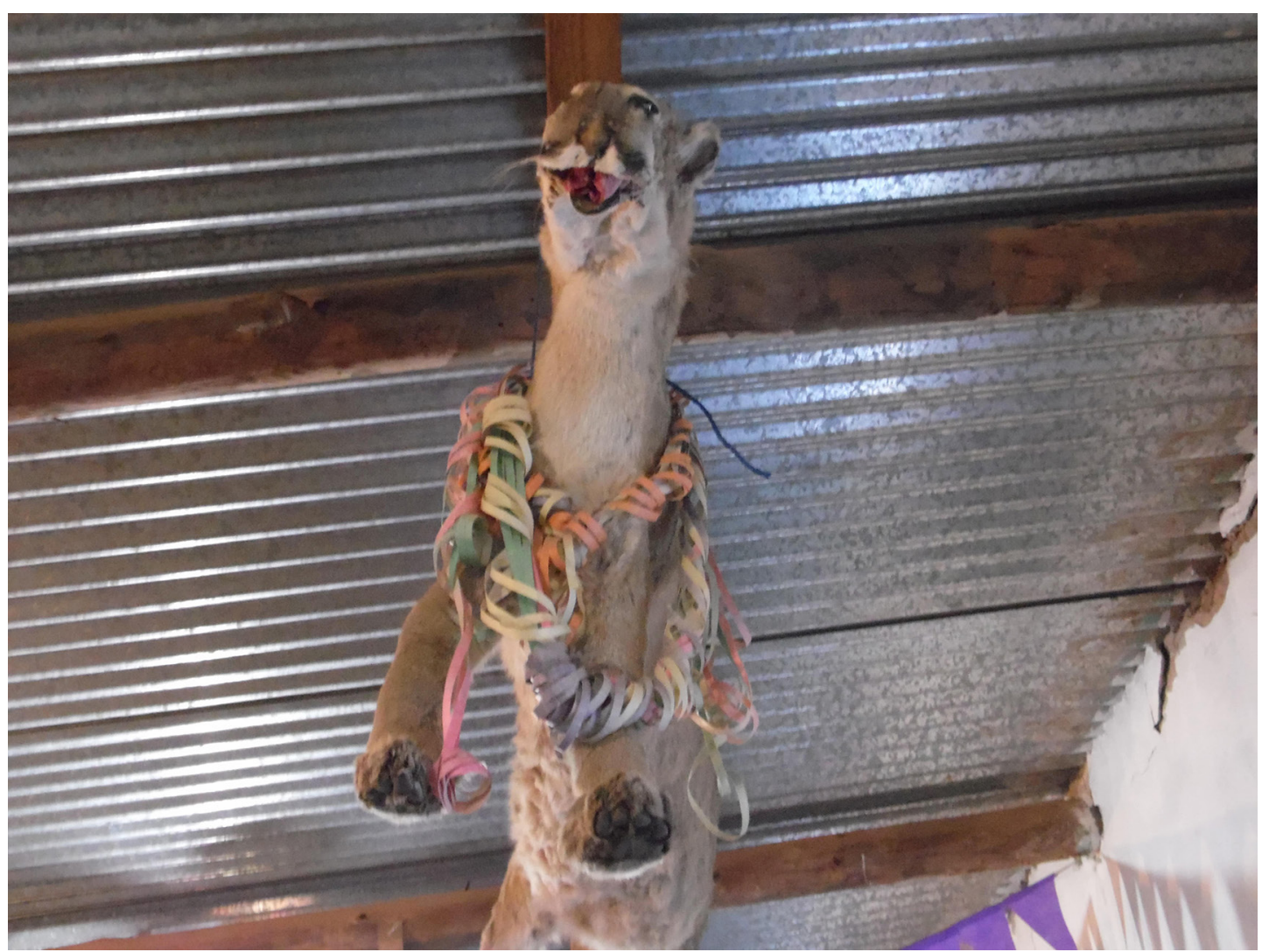

Figura 7. El puma carnavalero. 
vitalidad que se busca siempre en estos animales embalsamados.

En este mismo sentido, esta vecina también conserva un quirquincho embalsamado dentro del ropero de su habitación. De igual forma que el puma, es chayado durante el carnaval, siendo el encargado de propiciar monetariamente a la familia para que nunca falte la platita. Estos quirquinchos están rellenos generalmente de aserrín, a partir de una abertura en la panza por donde se sacan las vísceras. En la Quebrada de Humahuaca (provincia de Jujuy, Argentina) esta práctica es bastante habitual tanto en casas familiares como en despensas comerciales, y suelen colocarle además un billetito en la trompa, lo que lo vincula directamente con este sentido del multiplico del dinero. Se dice que al quirquincho deben crecerle los pelos, señal de que está contento y va a haber suerte. Esta cuestión no es menor si lo pensamos en los términos andinos de la vitalidad, de parecer vivo, de estar vivo. Grebe (1984) menciona para el norte de Chile que en el momento del cierre del carnaval suelen hacerse mesas, con fines propiciatorios, en donde aparece el quirquincho chayado y adornado. En dicha oportunidad también se le coloca un billete en su hocico. Todas estas acciones, al igual que en el norte argentino, están destinadas al éxito en los negocios y en las transacciones económicas.

\section{EI león en las fuentes coloniales}

Como lo mencionamos, diferentes fuentes coloniales señalan la importancia de los felinos para las cosmologías andinas, haciendo hincapié especialmente en su participación en rituales y en los modos de veneración. En términos generales aluden al uso de pieles y de tocados en bailes, así como refieren Garcilaso de la Vega (1963 [1609]), Betanzos (1987 [1551]), Molina (1989 [1573]), entre otros. Para el área atacameña, el extirpador de idolatrías Francisco de Otal en el siglo XVII registra la siguiente costumbre donde se vincula al león con prácticas rituales: "los mas indios de aquella provincia tienen una cueba donde para sus ydolos y ydolatrias estaban cabezas de leones carneros de (f.12) la tierra ay cus [¿cuys?]. coca chicha. quilaPana y la yervacata todo lo cual tienen para ofrezer a los dichos ydolos" (En: Castro 1993:352-353).

Nos interesa rescatar, además, la cita de Bartolomé Álvarez, por contener menciones cuanto menos sugestivas para nuestro problema de estudio:
Al león mochan según sus tontedades, viéndole pintado y esculpido, porque desta manera lo ponen: o en diversas maneras de vasijas de madera que tenían para beber en sus borracheras, o en los asientos en que se sientan, o en los edificios de sus casas, donde hay maderamientos. Esto lo ponen de manera que no parece lo que es conforme su intento, sino policía u ornato de lo que fabrican, y así nadie lo alcanza si no es [que] algunos sacerdotes, movidos de ver su dureza y tontedad, escudriñan todo lo que ven por el indicio y mala fama (Álvarez 1998[1588]:81, destacado nuestro).

Más allá de la importancia que se le asigna al león y su representación en diferentes soportes, nos interesa en especial la referencia a la presencia específica en los interiores de las casas, en particular en lo que se denominan "maderamientos", entendido como el conjunto de la estructura del techo, tijeras y costaneras. Es decir, el mismo emplazamiento que se observa para nuestro caso de estudio.

En el manuscrito anónimo de Huarochirí (Perú) puede leerse el siguiente pasaje:

Y pasando más adelante encontró con un león, el cual preguntado le respondió: que iba muy cerca la Diosa Cavillaca y que, si se daba mediana prisa la alcanzaría. Del aviso agradecido el sabio le bendijo diciendo: Tú serás respetado y temido de todos; y yo te asigno y señalo por verdugo y castigador en esta manera: que te doy facultad y licencia para que comas las llamas de los indios pecadores y más, que después de tu muerte has de ser honrado y temido en mucho. Porque, cuando te mataren, desollarán tu pellejo, sin cortarlo de la cabeza, la cual aderezarán, dejando allí la boca con su dentadura y lo demás embutirán de cosa que haga forma de cabeza y tus ojos los pondrán también en las cuencas que parezcan vivos; tus pies y manos quedarán pendientes del pellejo y la cola por el consiguiente y a su remate, un hilo para adornarla. Y el pellejo lo adobarán y sobarán y tras todo esto te subirán, así aderezado, sobre sus cabezas, poniendo la tuya encima de la suya y el pellejo, pies y manos cubrirá por detrás a quien 
así se pusiere. Lo cual harán en las fiestas más principales de manera que serán de esta suerte honrado y, sobre todo, añado que quien se quisiere adornar contigo ha de matar por entonces una llama y así ha de danzar y cantar contigo a cuestas (Ávila 2012 [1598?]:203, destacado nuestro).

Allende las diferencias con nuestro caso de estudio, son varios los puntos a rescatar de esta crónica. En primer lugar la importancia que tiene el aspecto vital en la condición del felino luego de ser sacrificado, tal que de esa manera conserve todas sus capacidades y poderes. Podemos asociar esto con la importancia asignada en Coranzulí a que el puma no debe destrozarse al ser cazado. Sin embargo, en el caso de Huarochirí (Perú), el pellejo con su cabeza serían utilizados para ser colocados sobre las personas para bailar en las festividades.

Millones y Mayer (2013) analizan específicamente los roles de los animales en dicho manuscrito, haciendo notar, por un lado, un claro vínculo entre las llamas y los pumas y, por otro, analizando cómo operarían estas pieles en esos contextos. Estos autores interpretan que "quien se viste de puma asume la identidad de tal animal, y eso incluye sus valencias sobrenaturales" (Millones y Mayer (2013:114). En un sentido similar, Bouysse-Cassagne (2018:701) entiende que vestir esas pieles consistía en "hacer desaparecer la forma humana bajo la del animal, era la de encarnar -en sentido pleno de la palabrael animal". Es decir, es un concepto andino muy diferente al "disfrazarse" (Millones y Millones 2011), en un sentido occidental. Como vimos, los pumas de Coranzulí se encuentran rellenos de vellón de lana de llama. Quizás sería interesante pensarlo en estos términos, ¿es la llama (de una manera metonímica) la que viste de puma, y este quien la atavía y la envuelve?

\section{Discusión: el puma en su red de relaciones}

Como hemos podido apreciar, el puma se constituye como un animal ambiguo y complejo que condensa múltiples sentidos y se integra a los diferentes entramados de la vida pastoril, de acuerdo con los momentos y contextos. Se conceptualiza como un ser sumamente poderoso, y como todas las entidades poderosas en los Andes, hay que controlarlas, ya que ese poder puede desmadrarse (Martínez 1983). Creemos que tanto los tratamientos que recibe el puma como el posicionamiento dentro de la casa, tienen que ver con controlar y direccionar ese poder, encauzándolo hacia la protección, el multiplico y la suerte tanto de la hacienda como del grupo familiar. Debemos retomar lo dicho al comienzo de este trabajo, en cuanto a las apreciaciones entre su estado vivo y exánime, cuando pasa a tener otra forma de existencia. De alguna manera, esa modulación de su potencia se logra post mortem a partir de ciertas operaciones que direccionan su vitalidad hacia el multiplico y la fertilidad de los pastores humanos y sus crías humanas y no humanas, pasando del dominio del cerro al doméstico.

El puma, entonces, se constituiría como un animal mediador entre los humanos, los animales de la hacienda y otras entidades no humanas, como Coquena. Mediando también entre la tensión interior/llama/doméstico/presa y exterior/puma/no doméstico/predador. Así, el puma envuelve a la llama promoviendo de esta forma el multiplico de la hacienda, al contener la potencia de lo almacenado en su interior.

El león se plantea también como un animal transgresor, al ingresar ya embalsamado a la casa familiar. En esta nueva locación transgrede un espacio que estando vivo, es decir, siendo animal del cerro, no hubiera accedido. Esto se relaciona, a nuestro entender, con el control de este animal. Al integrarlo a la familia se puede tener un dominio de su poder. Los poderes del felino siguen activos y si bien se vuelven propiciadores no dejan de ser riesgosos si no se proporciona el tratamiento adecuado, como ocurre con otros poderes genésicos en los Andes (ver Martínez 1983).

Las flores, los chimpus, el guano y la lana de llama del relleno lo vinculan de forma material y directa con los rebaños. Los primeros están asociados con el concepto de "suerte", en tanto poseen la capacidad de potenciar la producción y reproducción del ganado (Bugallo 2014, Mamani 2009). Lo que, a su vez, se vincula con las ideas de lo lleno, lo completo, lo envuelto, que actúan dentro del campo semántico de la fertilidad. Todo esto parece condensar un modo de relación donde un animal predador, con alta agencialidad, cría y es criado, integrándose a una matriz de sentidos asociados al multiplico, la suerte y la protección. Un fluir de las vidas animales -que tanto el pastor como el puma quieren- se multiplican, crecen y mueren, y vuelven a nacer; es en ese fluir, atravesado 
por la relación de afecto/predación, que se vuelven necesarias y urgentes las mediaciones.

\section{Agradecimientos}

Quiero agradecer a Lucila Bugallo quien enriqueció sustancialmente este trabajo con sus comentarios y preguntas. Asimismo Verónica Lema, Francisco Pazzarelli y Facundo Petit leyeron versiones preliminares y ayudaron a mejorarlo. Y, especialmente, a todas las familias coranzuleñas que me abrieron las puertas de sus casas y me hicieron partícipe de sus vidas.

\section{Referencias Citadas}

Albornoz, C.

1989 [1574-85] Instrucción para Descubrir todas las Guacas del Piru (1581-1585). Historia 16, Madrid, España.

Álvarez, B.

1998 [1588] De las Costumbres y Conversión de los Indios del Perú. Memorial a Felipe II (1588). Ediciones Polifemo, Madrid, España.

Arnold, D.

1998 "La casa de adobe y piedras del Inka: Género, memoria y cosmos en Qaqachaka”. En Hacia un Orden Andino de las Cosas, editado por D. Arnold, D. Jiménez y J. Yapita, pp. 31-108. Hisbol/ILCA, La Paz, Bolivia.

Arnold, D.

2016 "Territorios animados. Los ritos al Señor de los animales como una base ética para el desarrollo productivo en los Andes". En Símbolos, Desarrollo y Espiritualidades. El Papel de las Subjetividades en la Transformación Social, editado por A. E. Román-López Dollinger y H. T. Galarza Mendoza, pp. 111-159. ISEAT/U-PIEB, La Paz, Bolivia.

Aschero, C.A.

2000 "Figuras humanas, camélidos y espacios en la interacción circumpuneña". En Arte en las Rocas. Arte Rupestre, Menhires y Piedras de Colores en la Argentina, editado por M. M. Podestá, y M. de Hoyos, pp. 15-44. Sociedad Argentina de Antropología y Asociación Amigos del INAPL, Buenos Aires, Argentina.

Ávila, F. de.

2012 [1598?] Dioses y Hombres de Huarochirí. Narración Quechua Recogida por Francisco de Ávila (¿1598?), editado por J.M. Arguedas. Instituto de Estudios Peruanos. Lima, Perú.

Betanzos, J. de.

1987 [1551] Suma y Narración de los Incas. Atlas, Madrid, España.

Bouysse- Cassagne, $\mathrm{T}$.

2018 “'La piel que habito'. De algunos mecanismos de aparejamientos ontológicos entre humanos y animales en los Andes del sur". En Interpretando Huellas. Arqueología, Etnohistoria y Etnografía de los Andes y sus Tierras Bajas, pp. 697-719. Grupo Editorial Kipus, Cochabamba, Bolivia.

Bugallo, L.

1999 "La maison fléchée: conception de l’habitat sur le haut-plateau argentin". En Cultures et Habitats. Douze Contributions á une Ethnologie de la Maison, editado por E. Pierre, pp. XXXX. L' Harmattan, París, Francia.

Bugallo, L.

2014 "Flores para el ganado: Una concepción puneña del multiplico (puna de Jujuy, Argentina)". En Comprender los rituales ganaderos en los Andes y más allá: Etnografía de lidias, herranzas y arrierías, editado por ed. J. J. Rivera Andía, pp. 311-363. Bonner Amerikanistische Studien, Bonn.

Bugallo, L. y J. Tomasi.

2012 "Crianzas mutuas. El trato a los animales desde las concepciones de los pastores puneños (Jujuy, Argentina)". Revista Española de Antropología Americana 42, 1:205-224.

Bugallo, L. y M. Vilca.

2011 "Cuidando el ánimu: salud y enfermedad en el mundo andino (Puna y Quebrada de Jujuy, Argentina)". Nuevo Mundo Mundos Nuevos [En línea], Debates, 2011. Consultado el 01 abril 2012. URL: http://nuevomundo.revues.org/61781.

Cabrera, A.

1976 "Regiones Fitogeográficas Argentinas". En: Enciclopedia Argentina de Agricultura y Jardinería. Editorial Acme, Buenos Aires, Argentina.

Carrizo, J. A.

1959 Cancionero popular de Jujuy [1934]. Gobierno de la Provincia de Jujuy. Universidad Nacional del Tucumán. Tucumán, Argentina.

Castro, V.

1993 "Un proceso de extirpación de idolatrías en Atacama, siglo XVII". En Catolicismo y extirpación de Idolatrías. Siglos XVI-XVIII, editado por G. Ramos y H. Urbano, pp 347-366. Centro de Estudios Regionales Andinos "Bartolomé de las Casas", Cusco, Perú.

Cereceda, V.

2010 "Una extensión entre el altiplano y el mar. Relatos míticos chipaya y el norte de Chile". Estudios Atacameños 40:101:130.

Cruz, $\mathrm{P}$.

2002 "Entre pumas y jaguares. Algunas reflexiones acerca de la iconografía del valle de Ambato (Catamarca-Argentina)". Revista Andina 34:217-236.

Dransart, P.

2002 Earth, Water, Fleece and Fabric. An Ethnography and Archaeology of Andean Camelid Herding. Routledge, Londres.

Fujii, T.

1993 "El Felino, el Mundo Subterráneo y el Rito de Fertilidad: Tres Elementos Principales de la Ideología Andina". Senri ethnological studies 37:259-274.

García, S. y D. Rolandi.

2000 "Relatos y ritual referidos a la Pachamama en Antofagasta de la Sierra, Puna meridional argentina". Relaciones 25:7-25.

García, M., Gili, F., Echeverría, J., Belmonte, E. y V. Figueroa. 2018 “ $K$ ' $o a$, entidad andina de una planta y otros cuerpos. Una posibilidad interpretativa para ofrendas funerarias en la 
arqueología de Arica". Chungara. Revista de Antropología Chilena 50, 4:537-556.

Garcilaso de la Vega, I.

1963 [1609] Obras completas del Inca Garcilaso de la Vega. Biblioteca de Autores Españoles. Madrid.

Göbel, B.

2002 "La arquitectura del pastoreo: Uso del espacio y sistema de asentamientos en la Puna de Atacama (Susques)". Estudios Atacameños 23:53-76.

Gavilán Vega, V. y A.M. Carrasco.

2009 "Festividades andinas y religiosidad en el norte chileno". Chungara, Revista de Antropología Chilena 41 (1): 101-112.

González, A. R.

1972 "The felinic complex in Northwest Argentina". En The cult offeline. A Conference in Precolumbian Iconography, editado por E. Benson, pp. 117-138. Dumbarton Oaks, Washington.

Gose, P.

1991 "House Rethatching in an Andean Annual Cycle: Practice, Meaning, and Contradiction". American Ethnologist 18, 1:39-66.

Grebe, M. E.

1984 "Etnozoología andina: Concepciones e interacciones del hombre andino con la fauna altiplánica". Estudios Atacameños 7:335-347.

Grebe, M.E.

1989-1990 "El culto a los animales sagrados emblemáticos en la cultura aymara de Chile". Revista Chilena de Antropología 8:35-51.

Mamaní, L.

2009 "Entre el zorro y el cóndor: producción ganadera y simbolismo en la Quebrada de Humahuaca". Cuadernos FHyCS-UNJu 36:159-176.

Manríquez, V.

1999 "El término Ylla y su potencial simbólico en el Tawantinsuyu. Una reflexión acerca de la presencia inca en Caspana (río Loa, desierto de Atacama)". Estudios Atacameños 18:107-118.

Mariscotti de Görlitz, A. M.

1978 "Pachamama Santa Tierra. Contribución al estudio de la religión autóctona en los Andes centro-meridionales". Indiana 8:1-430.

Martínez, G.

1983 "Los dioses de los cerros en los Andes". Journal de la Société des Américanistes 69:85-115.

Millones, L. y R. Mayer.

2013 Dioses y animales sagrados de los Andes peruanos (Manuscrito de Huarochiri). Ediciones Doce Calles y Universidad Pablo de Olavide. Madrid, España.
Millones, L. y M. Millones.

2011 "Zoología fantástica a través de textos sagrados de Andes y Mesoamérica". Perspectivas Latinoamericanas 8:1-23.

Molina, C. de.

1989 [1573] "Relación de las Fábulas y Ritos de los Incas". En Fábulas y mitos de los incas, editado por P. Duviols y H. Urbano. Historia 16, Madrid.

Morgante, M. G.

2001 "La narrativa animalistica y la mitologia del trickster en la Puna jujeña: la figura del zorro". Anthropologica del Departamento de Ciencias Sociales, 19: 121-146.

Palacios Ríos, F.

1977 '....Hiwasaha uywa uywataña, uka uywaha hiwasaru uyusitu'. Los pastores aymara de Chichillapi. Tesis de Maestría, Pontificia Universidad Católica de Perú, Lima, Perú.

Pazzarelli, F.

2019 "Looks Like Viscera: Folds, Wraps, and Relations in the Southern Andes". Social Analysis 63, 2:45-65.

Pérez Gollán, J. A.

1986 "Iconografía religiosa andina en el noroeste argentino". Bulletin de l'Institut Français d'Etudes Andines, 15(3-4):61-72.

Rivet, C. y J. Tomasi.

2016 "Casitas y casas mochas: Los antiguos y los abuelos en sus arquitecturas (Coranzulí y Sus-ques, provincia de Jujuy, Argentina)". En Wakas, diablos y muertos: alteridades significantes en el mundo andino, editado por L. Bugallo y M. Vilca. Ediciones de la Universidad Nacional de Jujuy, Instituto Francés de Estudios Andinos. Jujuy, Argentina.

Sendón, $\mathrm{P}$.

2004 "El wasichakuy de Marcapata. Ensayo de interpretación de una 'costumbre' andina”. Revista Andina 39, 2:51-73.

Tomasi, J.

2011 Geografías del pastoreo. Territorios, movilidades y espacio doméstico en Susques (provincia de Jujuy). Tesis de doctorado en Geografía, Facultad de Filosofía y Letras, Universidad de Buenos Aires, Buenos Aires, Argentina.

Tschopik, H.

1951 "The Aymara of Chucuito, Perú". Anthropological Papers of the American Museum of Natural History 44, 2.

Villar, P.

2015 "El lugar del puma. Representaciones sociales y cultura material en el valle del Cajón (Catamarca, Argentina)". KULA. Antropólogos del Atlántico Sur 12:30-40.

Yacobaccio, H., Madero, C. y M. Malmierca.

1998 Etnoarqueología de pastores surandinos. Grupo de Zooarqueología de Camélidos. Buenos Aires.

Zuidema, T.

1989 "El león en la ciudad. Símbolos reales de transición en el Cusco". Reyes y Guerreros: Ensayos de Cultura Andina.

\section{Notas}

1 Este ser polisémico, dependiendo de los contextos y épocas ha sido asociado al culto a la deidad solar y al de los antepasados (Pérez Gollán 1986), a los fenómenos meteorológicos como lluvia y granizo (Mariscotti de Görlitz 1978), con el culto a los antepasados y sus fuerzas fecundantes (Aschero 2000, Cruz 2002), con el poder político (Zuidema 1989), con el mundo subterráneo, los poderes genésicos y con el universo saqra (Cruz 2002, Fujii 1993) y con el culto al felino en el noroeste argentino (González 1972).

2 Al puma también se lo suele nombrar localmente como león o gato. De hecho león es el término que utilizan los españoles en las crónicas coloniales para designar a dicho animal. 
3 Probablemente este silencio se deba a la alta agencialidad que presenta el puma embalsamado, en tanto un ser con capacidades poderosas que deben controlarse, como nos sugirió Bárbara Göbel (Com. Pers. Congreso LASA 2017).

4 Coquena es una entidad protectora de los animales silvestres, que generalmente viste de vicuña (García y Rolandi 2000) y que sanciona a los cazadores ambiciosos. A su vez, Arnold (2016:115) se refiere a esta entidad como el "ser tutelar de los cerros".

5 En los últimos tiempos el puma ha acechado con asiduidad las haciendas. De hecho esto fue motivo de notas periodísticas por la preocupación que expresaban los vecinos de la zona, reclamando a las autoridades algún tipo de intervención (ver periódico El Tribuno, Jujuy de 7/5/2018). Las personas más ancianas de la comunidad expresan que los jóvenes ya no van al campo, no se encargan de las haciendas y por eso castiga coquena, llevándose la hacienda.

6 Hemos evitado citar los nombres de las personas entrevistadas en pos de mantener su anonimato, siguiendo su voluntad.

7 Se ha evitado hacer mención de nombres propios para preservar la identidad de las personas entrevistadas

8 Se ha evitado hacer mención de nombres propios para preservar la identidad de las personas entrevistadas

9 Se ha evitado hacer mención de nombres propios para preservar la identidad de las personas entrevistadas

10 El rol de la mujer en relación con el puma es un tema que se esboza importante y que necesita ser profundizado desde el trabajo de campo etnográfico.

11 Se ha evitado hacer mención de nombres propios para preservar la identidad de las personas entrevistadas
12 Es una hierba que crece en los cerros. A veces suele comerlo la hacienda. Cuando el animal es una cría puede matarlo.

13 El guano es reconocido como un fertilizante de la tierra, usado en los rastrojos (pequeñas huertas familiares), a su vez es utilizado como combustible y en la mezcla de barro de los adobes.

14 Nos han referido con el término soquero al cuerpo del animal cuando le extraen el guano, quedando seco y duro. Morgante (2001) define al soquero como un reciente confeccionado con el cuero seco de un animal. Bugallo (com. pers. 2019) nos ha sugerido que quizás ese vocablo provenga de soqa o soq'a que significa algo que no está completo.

15 En términos estrictos, Pazzarelli se refiere a los animales del rebaño, pero consideramos que se puede extender estar idea al caso del puma.

16 Ritual que se realiza una vez terminado el techo de la casa y que consiste en abrir un pozo (llamado pachero, juire o pujio) debajo de la cumbrera de donde cuelga un huevo (idealmente de suri, en su defecto puede ser de gallina) envuelto en una redecilla de lanas de colores. Se confeccionan flechas con ramas de un arbusto llamado tola, a las que se atan las mismas lanas del huevo. La familia y los invitados (todos los que trabajaron en la hechura del techo) se colocan en círculo alrededor del pozo y por turnos van tirando las flechas con el objetivo de partir el huevo y que su contenido caiga como ofrenda dentro del pachero.

17 Esta consideración del felino como protector de la casa fue también registrada entre los aymaras (Mariscotti de Görlitz 1978).

18 Estos atributos que enarbolan los pumas fueron colocados en oportunidades diferentes señaladas a lo largo del tiempo. 